\title{
Giant Pseudoaneurysm as a delayed Surgical Complication in a Patient Operated on a Giant Neuroma of the Vagus Nerve: Case Report and Management Considerations
}

\section{Pseudoaneurisma gigante como complicação cirúrgica em paciente operado com neuroma gigante do nervo vago: relato de caso e considerações}

\author{
Demian Manzano-Lopez ${ }^{1}$ Pablo Rubino ${ }^{2}$ Pablo Mendivil Teran ${ }^{1}$ Jesús Lafuente Baraza ${ }^{1}$ \\ Gerardo Conesa Bertran ${ }^{1}$ \\ ${ }^{1}$ Neurosurgery Department, Hospital del Mar, Parc de Salut Mar, \\ Barcelona, Spain \\ ${ }^{2}$ Neurosurgery Department, Hospital El Cruce, Dr. Néstor Kirchner, \\ Buenos Aires, Argentina

\begin{abstract}
Address for correspondence Demian Manzano Lopez Gonzalez, MD, Neurosurgery Department, Hospital del Mar, Parc de Salut Mar, Passeig Maritim 23-25, Barcelona, Spain Zip: 08003

(e-mail: 95324@parcdesalutmar.cat; dml8923@yahoo.es).
\end{abstract}

Arq Bras Neurocir 2015;34:321-326.

\section{Abstract \\ Keywords \\ - posterior fossa approach \\ - pseudoaneurysm \\ - vertebral artery \\ - endovascular treatement \\ Resumo \\ Palavras-chave \\ - acesso à fossa posterior \\ - pseudoaneurisma \\ - artéria vertebral \\ - tratamento endovascular}

The vertebral artery has four segments. The horizontal portion of the V3 segment is the most exposed portion of the vertebral artery to potential iatrogenic injuries during surgical approaches to the posterior fossa. We present an unusual case of a patient who was operated on a giant neuroma of the left vagus nerve, with incidental vertebral artery iatrogenic injury, the development of a delayed giant pseudoaneurysm, and the treatment for this complication. We conclude that endovascular treatment may be a good option for the management of this serious surgical complication.

A artéria vertebral tem quarto segmentos. A porção horizontal do segmento V3 é a mais exposta a potenciais lesões iatrogênicas durante procedimento cirúrgico de acesso à fossa posterior. Apresentamos caso incomum de paciente submetido à cirurgia para neuroma gigante no nervo vago esquerdo, com acidental lesão da artéria vertebral iatrogênica, desenvolvimento de posterior pseudoaneurisma gigante e tratamento para esta complicação. Concluímos que o tratamento endovascular pode ser uma boa opção para o cuidado desta grave complicação cirúrgica. received

January 20, 2014

accepted

August 7, 2015

published online

October 28, 2015
DOI http://dx.doi.org/

10.1055/s-0035-1564580. ISSN 0103-5355.
Copyright $@ 2015$ by Thieme Publicações License terms

Ltda, Rio de Janeiro, Brazil

ㄷ) (i) $\ominus$ (\$) 


\section{Introduction}

The vertebral artery (VA) has four segments. Segment V1 runs from the vertebral artery origin to the C- 6 transverse process. Segment V2 is the portion of the artery that courses through the C-6 to the C-2 transverse processes. Segment V3 runs from the $\mathrm{C}-2$ transverse process to the entry in the dura mater. The segment $\mathrm{V} 4$, which is the intradural portion of the artery, ends in the confluence with the basilar artery. ${ }^{1-8}$

The V3 segment, or suboccipital segment, is in turn divided into three parts. First, the vertical part runs between the $\mathrm{C}-1$ and $\mathrm{C}-2$ transverse processes and contains the proximal loop. The second is the horizontal part, formed by the segment of the artery that courses in the groove of the posterior arch of the atlas, and that contains the distal loop. Third, there is the oblique part, which projects superomedially from $\mathrm{C}-1$ and enters the dura mater. ${ }^{1-3,7}$

The horizontal part of the V3 segment is the most exposed portion of the vertebral artery to potential iatrogenic injuries during surgical approaches to the posterior fossa. ${ }^{3,7}$

We present an unusual case of a patient who was operated on a giant neuroma of the left vagus nerve, with incidental vertebral artery iatrogenic injury, the development of a delayed giant pseudoaneurysm, and the treatment for this complication.

\section{Case Report}

A 34-year-old man with history of neurofibromatosis extending throughout the central and peripheral nervous system had been operated on multiple spinal dorsal schwannomas that caused cord compression. He presented with worsening of gait disturbance in a myelopathy context due to his neurological history. Upon physical examination, the stability of his myelopathy was verified and, instead, we found an affectation of the $7^{\text {th }}, 8^{\text {th }}, 9^{\text {th }}$ and $10^{\text {th }}$ left cranial nerves, together with a worsening of the previous gait disturbance.

Upon cranial magnetic resonance (MR), two tumors were found. Both were located bilaterally in the cerebellomedullary cisterns. The right tumor was small and of insignificant size. The left tumor was very voluminous, with significant brain stem compression, and with important extracranial extension through the jugular foramen. We suspected the tumors were lower cranial nerves neuromas, most probably from the vagus nerve on the left side (- Fig. $\mathbf{1}$ ).
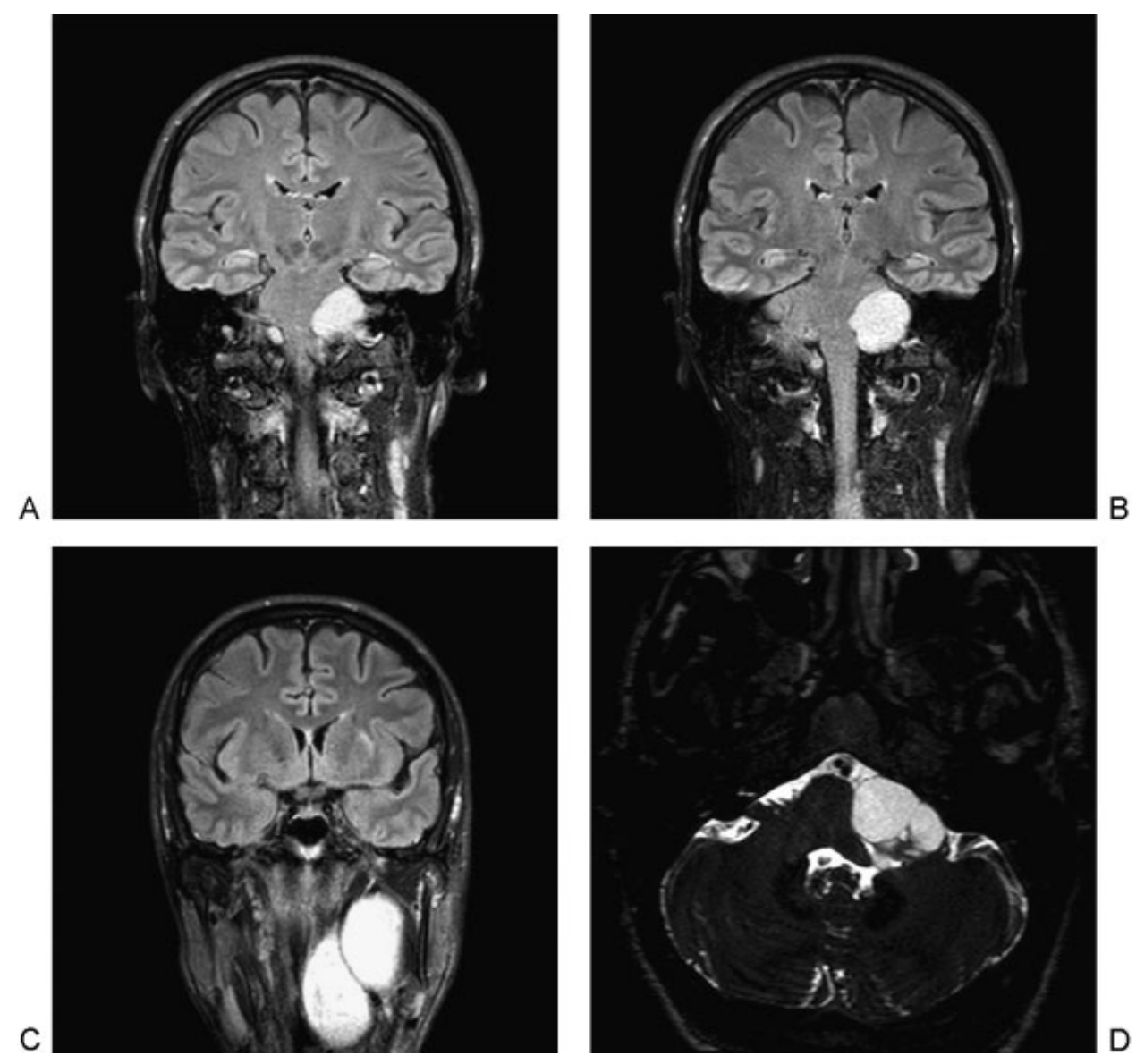

Fig. 1 Preoperative cranial MR. (A) Coronal view showing bilateral lower cranial nerves neuromas located at both cerebellomedullary cisterns. The right one is very small and insignificant in size. On the other hand, the left tumor shows significant size and compression of the brain stem. (B) Coronal view showing compression and distortion of the brain stem by the left vagus nerve neuroma. No hydrocephalus is apparent. (C) Coronal view showing important extracranial extension of the left tumor through the jugular foramen. (D) Axial view showing the left tumor at the cerebellomedullary cistern. The tumor is multilobulated and shows significant brain stem compression. 

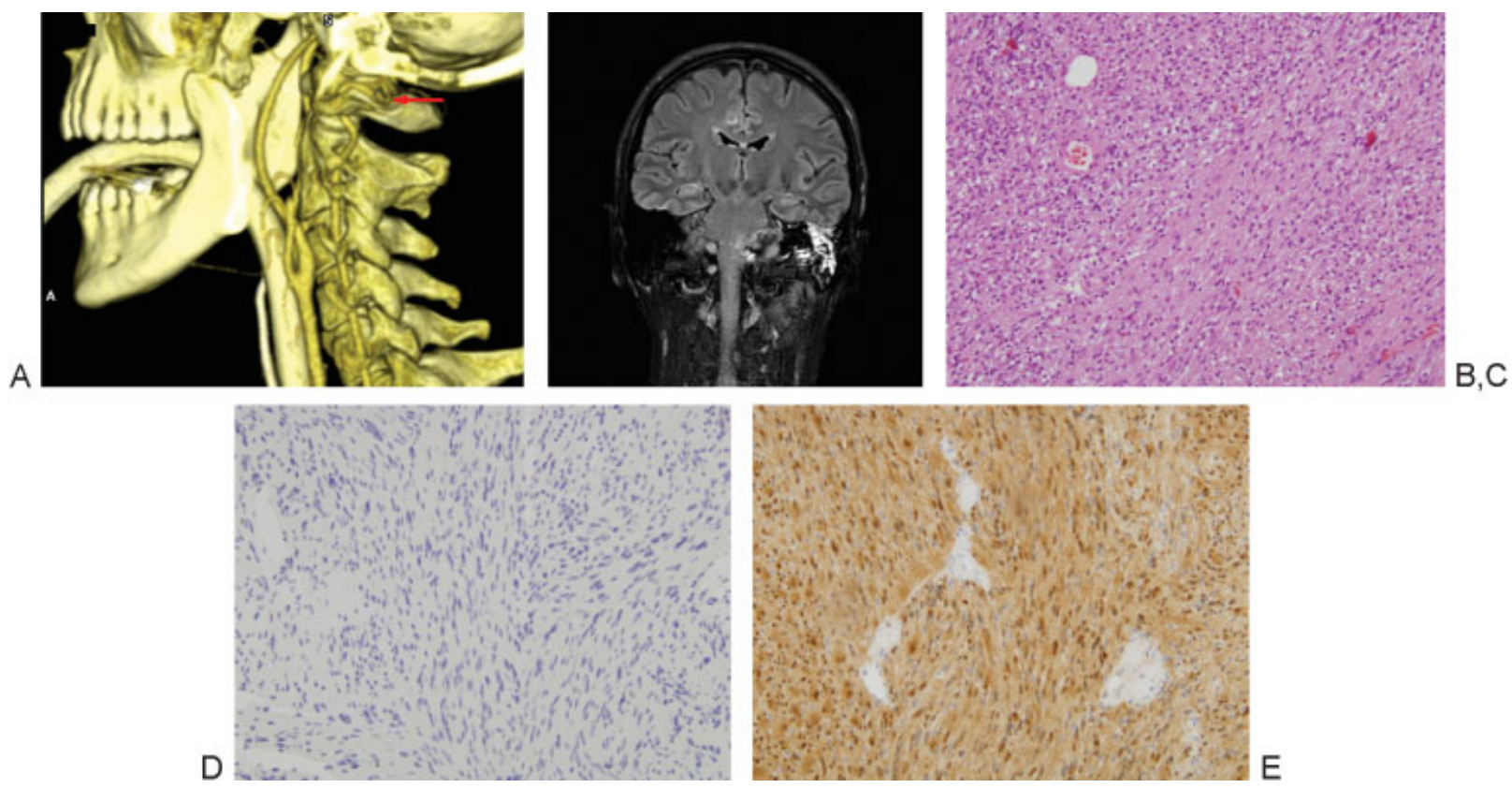

Fig. 2 Postoperative studies. (A) Immediate postoperative Angio-CT scanner performed to rule out any complication on the vertebral artery injured during surgery. No thrombosis, dissection, pseudoaneurysm, or any other complication develop in the immediate postoperative period. Red arrow showing indemnity of the left vertebral artery at V3 portion. (B) Postoperative MR showing gross subtotal removal of the intracranial portion of the left tumor. A very small portion of the tumor had to be left because of its adherences to the facial nerve and brain stem, when the intraoperative neurophysiological potentials were affected. The procedure achieved satisfactory brain stem decompression and restoration of normal anatomy. Histopathological findings confirm schwannoma. (C) Compact cellular pattern in Antoni A fiber areas (hematoxylin-eosin stain). (D) Negativity for neurofilaments. (E) Positivity for S100 protein.

No new spinal tumors were found upon the spinal MR.

The patient underwent surgery to achieve brain stem decompression.

We performed a lateral suboccipital retrosigmoid approach. Patient positioning was "park bench," and intraoperative neurophysiological monitoring was set up. During muscular dissection, the left vertebral artery was accidentally injured in its third portion. The hemorrhage was controlled with tamponade and hemostatic agents, and the rest of the surgery was performed without incidents. We achieved a gross subtotal removal of the intracranial tumor extension, obtaining satisfactory brain stem decompression. A very little portion of the tumor was left because of its adherences to the facial nerve and the brain stem, when intraoperative neurophysiological potentials were affected (left $7^{\text {th }}$ cranial nerve and right upper limb) (-Fig. 2B).

We employed an Angio-CT scanner in the immediate postoperatory period to rule out any complication of the injured vertebral artery. We found no thrombosis, dissection, pseudoaneurysm, or any other complication. The CT-angiography showed indemnity of both vertebral arteries ( - Fig. 2A).

The postoperative course was favorable and the patient recovered from the $7^{\text {th }}$ and $8^{\text {th }}$ cranial nerve affectation and his gait disturbance diminished. On the other hand, the $9^{\text {th }}$ and $10^{\text {th }}$ cranial nerves remained affected, and the patient was sent to rehabilitation therapy.

The pathologist reported schwannoma, confirming the presumptive diagnosis (-Figs. 2C, 2D, 2E).
Four weeks later, the patient developed a sudden painful lump with important tension on the left retroauricular region. A CT scanner showed a soft tissue hematoma

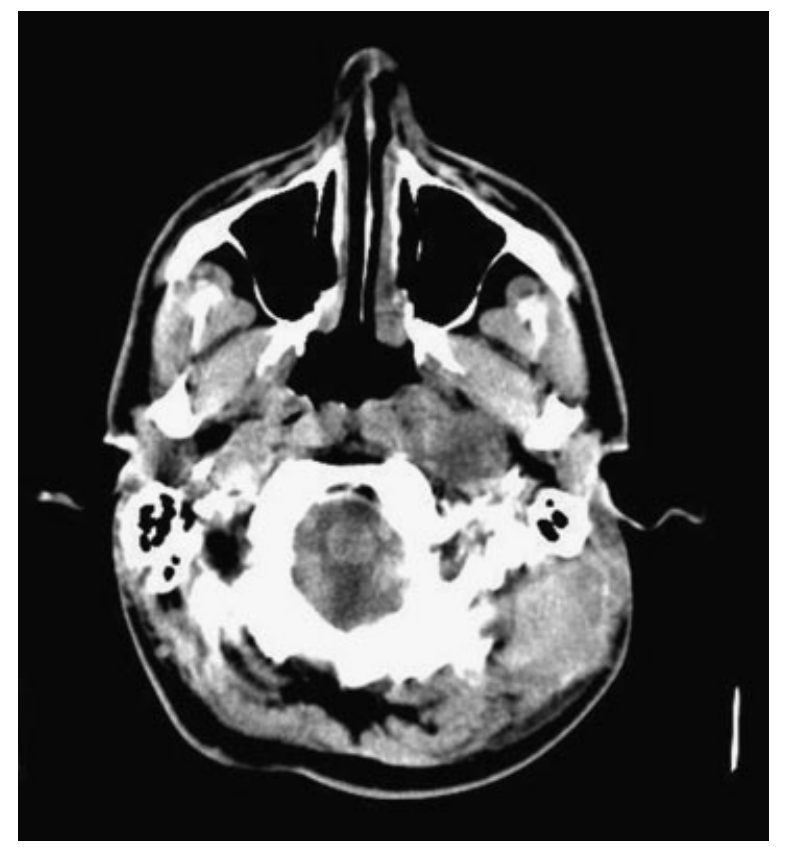

Fig. 3 A CT scanner four weeks after surgery showing a soft tissue hematoma on the left retroauricular region as the patient develops a sudden painful lump with important tension. 

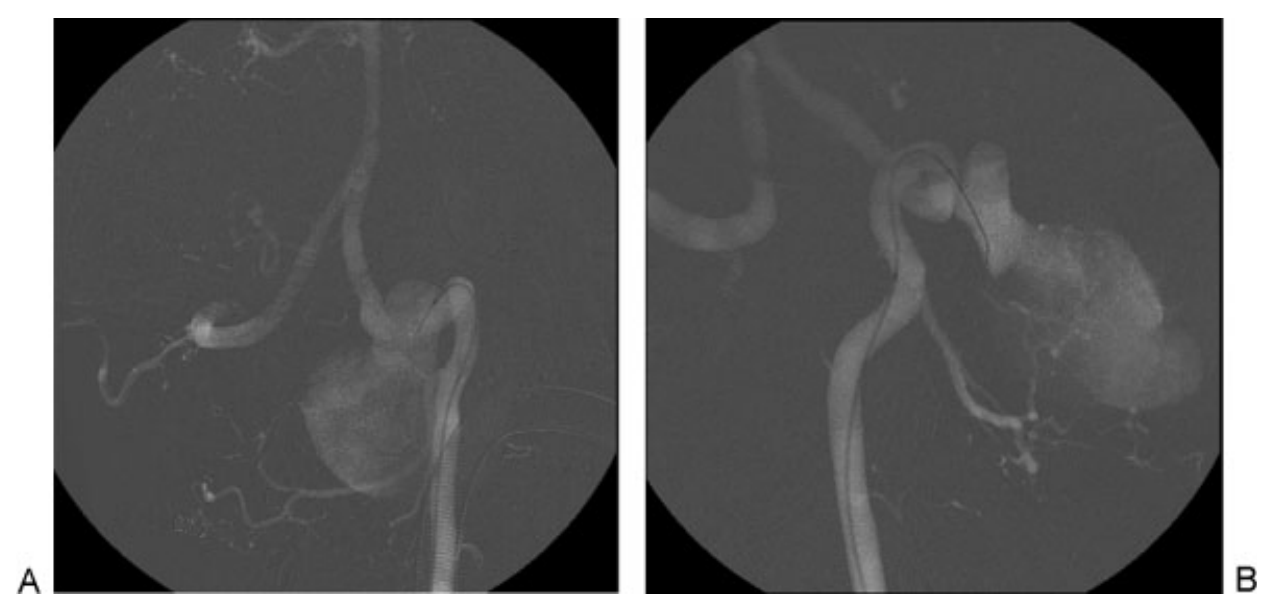

Fig. 4 An angiogram demonstrates a giant pseudoaneurysm originating from the horizontal portion of the V3 segment of the left vertebral artery. The pseudoaneurysm is $25 \times 40 \mathrm{~mm}$ in size, and has a proximal and a distal lobule.

(-Fig. 3). An angiogram was made and it demonstrated a giant pseudoaneurysm of the $\mathrm{V} 3$ portion of the left vertebral artery ( - Fig. 4). The pseudoaneurysm was treated by coil embolization in the same act. The postembolization angiogram showed exclusion of the pseudoaneurysm and permeability of the vertebral artery (-Fig. 5).

The postoperative course was favorable and the lump diminished in size and tension, no longer inflicting pain on the patient.

Three months later, the patient no longer had the lump.

Two years later, the postoperative studies, MR-angiography, and Angiogram, still showed exclusion of the pseudoaneurysm and permeability of the vertebral artery (-Fig. 6).

\section{Discussion}

Although surgical injuries on the vertebral artery (SIVA) are rare, they can lead to various different clinical outcomes. If the initial hemorrhage is controlled well, the patient may remain asymptomatic (especially if the injured vertebral artery is not dominant or the patient has good intracranial and extracranial collateral circulation). ${ }^{9}$ On the other hand, surgical injuries on the vertebral artery may also lead to catastrophic consequences when they are associated with serious complications, such as arteriovenous fistula, lateonset hemorrhage, pseudoaneurysm, thrombosis, embolism, cerebral ischemia, and death. ${ }^{8,10-15}$

Once the injury occurs, the intraoperative treatment options are: hemostatic tamponade/compression, microvascular repair of the injured artery, and ligation of the vertebral artery.

Direct hemostatic tamponade/compression may be an effective, quick, and easy measure. However, several cases of delayed hemorrhage and arteriovenous fistula formation have been reported. ${ }^{16,17}$ Microvascular primary repair restores normal blood flow and minimizes the risk of immediate or delayed ischemic complications. ${ }^{16,17}$ However, it is technically demanding. Ligation of the vertebral artery is associated with significant morbidity and mortality, such as
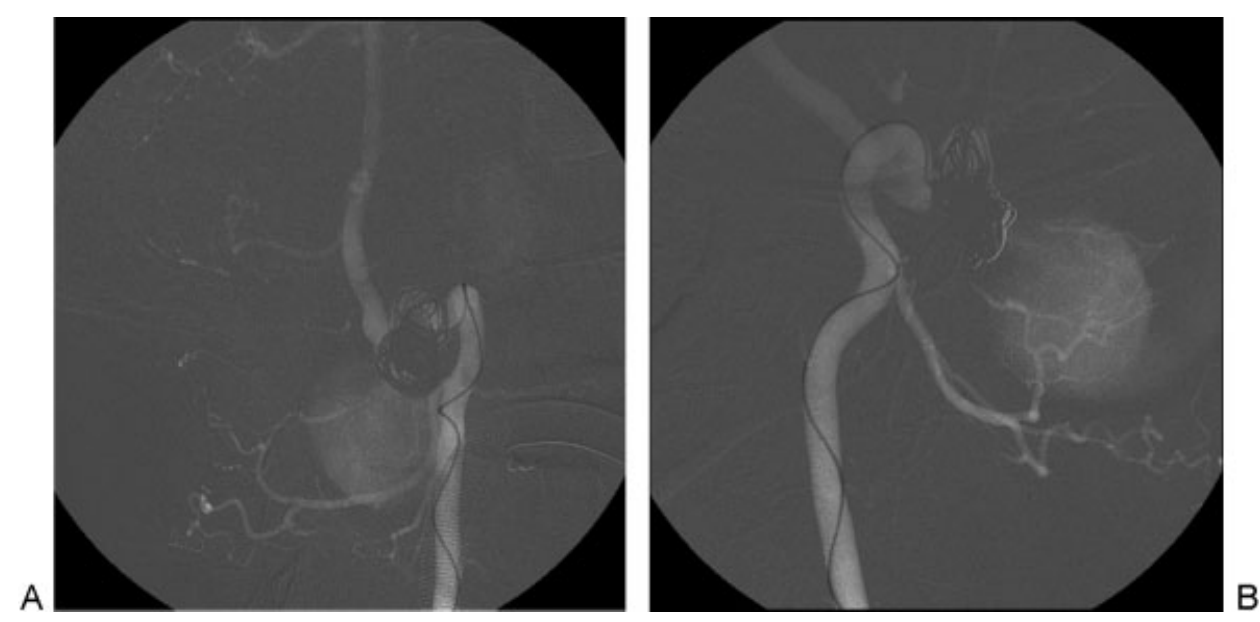

Fig. 5 Endovascular coil embolization of the pseudoaneurysm is performed. Only the proximal lobule of the pseudoaneurysm is treated. A complete exclusion of the pseudoaneurysm is achieved and vertebral artery permeability is maintained. Immediately after the procedure the patient is relieved from pain. Three months after the endovascular procedure, the patient no longer has the lump. 

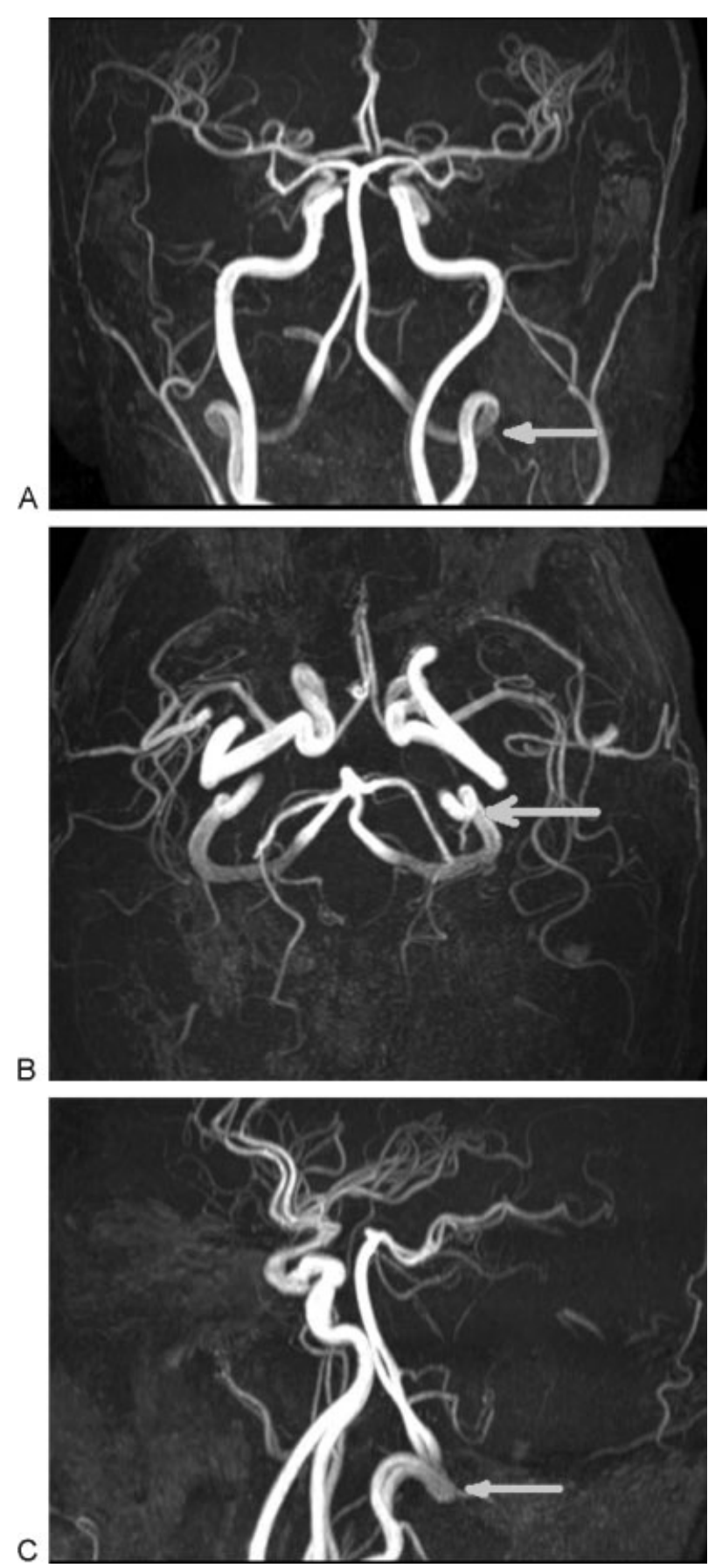

Fig. 6 MR-Angiography two years after the embolization still shows exclusion of the pseudoaneurysm and permeability of both vertebral arteries. Arrows show the horizontal portion of the $\mathrm{V} 3$ segment of the left vertebral artery where the pseudoaneurysm developed.

Wallenberg's syndrome, cerebellar infarction, cranial nerve paresis, quadriparesis, and hemiplegia. . $^{12,18,19}$

Immediate angiogram is recommended after surgical vertebral artery injury to detect vascular complications and confirm adequate collateral circulation to the brain. However, a normal angiogram after SIVA does not rule out the subsequent formation of a pseudoaneurysm, and there have been reports of rebleeding days and even years after surgery. ${ }^{20}$ In this situation, patients can be followed up with MR-angiography or CT-angiography to evaluate the vessel situation and exclude the possibility of a growing pseudoaneurysm formation.

Progressively, there has been greater introduction of endovascular management, such as coil embolization, stent-assist coil embolization, and the use of stent grafts or covered stents. ${ }^{11,13,15,18}$ An ideal situation would be to be able to rely on an intraoperative angiogram and an endovascular team for the immediate evaluation and treatment of the SIVA. However, this is not the usually standard situation.

On a separate issue, considering that the horizontal portion of the V3 segment of the vertebral artery is the most exposed to potential injuries during surgical approaches to the posterior fossa, it is important to briefly comment on patient positioning during the surgery to help avoid this serious complication. Perhaps Neurosurgery is the surgical specialty in which patient position is one of the most critical aspects of the surgical act itself. The case we present is a good example of this. Patient positioning can minimize the risk of surgical injury to the horizontal portion of the V3 segment of the VA. It is important to open up the interval between the artery and the occipital bone with adequate neck flexion, head rotation, and dropping the vertex of the head toward the floor. These maneuvers displace the superior surface of the horizontal portion of the V3 segment away from the lower occiput, minimizing the risk of arterial injury. $3,6,21,22$

\section{Conclusion}

The horizontal portion of the V3 segment of the vertebral artery is the most exposed to accidental surgical injuries during surgical approaches to the posterior fossa.

Patient positioning is a matter of utmost importance in preventing potentially fatal complications during this type of surgery.

If intraoperative vertebral artery injury occurs, initial control of bleeding may be obtained with hemostatic tamponade. However, there is a risk of developing a growing pseudoaneurysm leading to possibly fatal bleeding. An angiogram or CT-angiography should be performed in such cases, although if normal, these cannot rule out delayed formation of pseudoaneurysm.

The endovascular treatment is a good option in the management of this serious surgical complication.

\section{References}

1 Aota Y, Honda A, Uesugi M, et al. Vertebral artery injury in C-1 lateral mass screw fixation. Case illustration. J Neurosurg Spine 2006;5(6):554

2 George B, Cornelius J. Vertebral artery: surgical anatomy. In: Spetzler RF (ed): Operative Techniques in Neurosurgery. Philadelphia: WB Saunders; 2001:168-181

3 Ulm AJ, Quiroga M, Russo A, et al. Normal anatomical variations of the $V_{3}$ segment of the vertebral artery: surgical implications. J Neurosurg Spine 2010;13(4):451-460 
4 Argenson C, Francke JP, Sylla S, Dintimille H, Papasian S, di Marino V. The vertebral arteries (segments V1 and V2). Anat Clin 1980; 2:29-41

5 Francke JP, Dimarino V, Pannier M, Argenson C, Libersa C. The vertebral arteries (arteria vertebralis): the V3 atlanto-axoidal and V4 intracranial segments-collaterals. Anat Clin 1981; 2:229-242

6 George B. Exposure of the upper cervical vertebral artery. In: Dickman CA, Spetzler RF, Sontag VKH (eds): Surgery of the Craniovertebral Junction. New York: Thieme; 1998:545-567

7 Tubbs RS, Shah NA, Sullivan BP, Marchase ND, Cohen-Gadol AA. Surgical anatomy and quantitation of the branches of the V2 and V3 segments of the vertebral artery. Laboratory investigation. J Neurosurg Spine 2009;11(1):84-87

8 Peng CW, Chou BT, Bendo JA, Spivak JM. Vertebral artery injury in cervical spine surgery: anatomical considerations, management, and preventive measures. Spine J 2009;9(1):70-76

9 Inamasu J, Guiot BH. Iatrogenic vertebral artery injury. Acta Neurol Scand 2005;112(6):349-357

10 Prabhu VC, France JC, Voelker JL, Zoarski GH. Vertebral artery pseudoaneurysm complicating posterior C1-2 transarticular screw fixation: case report. Surg Neurol 2001;55(1):29-33, discussion 33-34

11 Cosgrove GR, Théron J. Vertebral arteriovenous fistula following anterior cervical spine surgery. Report of two cases. J Neurosurg 1987;66(2):297-299

12 Shintani A, Zervas NT. Consequence of ligation of the vertebral artery. J Neurosurg 1972;36(4):447-450

13 Daentzer D, Deinsberger W, Böker DK. Vertebral artery complications in anterior approaches to the cervical spine: report of two cases and review of literature. Surg Neurol 2003;59(4):300-309, discussion 309
14 Gluf WM, Schmidt MH, Apfelbaum RI. Atlantoaxial transarticular screw fixation: a review of surgical indications, fusion rate, complications, and lessons learned in 191 adult patients. J Neurosurg Spine 2005;2(2):155-163

15 Méndez JC, González-Llanos F. Endovascular treatment of a vertebral artery pseudoaneurysm following posterior $\mathrm{C} 1-\mathrm{C} 2$ transarticular screw fixation. Cardiovasc Intervent Radiol 2005;28(1):107-109

16 de los Reyes RA, Moser FG, Sachs DP, Boehm FH. Direct repair of an extracranial vertebral artery pseudoaneurysm: case report and review of the literature. Neurosurgery 1990;26(3):528-533

17 Neo M, Fujibayashi S, Miyata M, Takemoto M, Nakamura T. Vertebral artery injury during cervical spine surgery: a survey of more than 5600 operations. Spine 2008;33(7):779-785

18 Choi JW, Lee JK, Moon KS, et al. Endovascular embolization of iatrogenic vertebral artery injury during anterior cervical spine surgery: report of two cases and review of the literature. Spine 2006;31(23):E891-E894

19 Golueke P, Sclafani S, Phillips T, Goldstein A, Scalea T, Duncan A. Vertebral artery injury-diagnosis and management. J Trauma 1987;27(8):856-865

20 Diaz-Daza O, Arraiza FJ, Barkley JM, Whigham CJ. Endovascular therapy of traumatic vascular lesions of the head and neck. Cardiovasc Intervent Radiol 2003;26(3):213-221

21 Bruneau M, George B. Foramen magnum meningiomas: detailed surgical approaches and technical aspects at Lariboisière Hospital and review of the literature. Neurosurg Rev 2008;31(1):19-32, discussion 32-33

22 Kawashima M, Tanriover N, Rhoton AL Jr, Ulm AJ, Matsushima T. Comparison of the far lateral and extreme lateral variants of the atlanto-occipital transarticular approach to anterior extradural lesions of the craniovertebral junction. Neurosurgery 2003;53(3): 662-674, discussion 674-675 